\title{
Effect of Moderate UVC Irradiation on Bovine Serum Albumin and Complex with Antimetabolite 5-Fluorouracil: Fluorescence Spectroscopic and Molecular Modelling Studies
}

\author{
Shanmugavel Chinnathambi, ${ }^{1,2}$ Subramani Karthikeyan, ${ }^{3}$ Devadasan Velmurugan,,4 \\ Nobutaka Hanagata, ${ }^{2,5}$ Prakasarao Aruna, ${ }^{1}$ and Singaravelu Ganesan ${ }^{1}$ \\ ${ }^{1}$ Department of Medical Physics, Anna University, Chennai 600 025, India \\ ${ }^{2}$ Nanotechnology Innovation Station, National Institute for Materials Science, 1-2-1 Sengen, Tsukuba, Ibaraki 305-0047, Japan \\ ${ }^{3}$ Centre of Advanced Study in Crystallography and Biophysics, University of Madras, Chennai 600 025, India \\ ${ }^{4}$ Bioinformatics Infrastructure Facility, University of Madras, Chennai 600 025, India \\ ${ }^{5}$ Graduate School of Life Science, Hokkaido University, N10W8 Kita-ku, Sapporo 060-0812, Japan
}

Correspondence should be addressed to Nobutaka Hanagata; nobutaka.hanagataa@nims.go.jp and Singaravelu Ganesan; ganesansingaravelu@gmail.com

Received 15 October 2014; Revised 4 January 2015; Accepted 7 January 2015

Academic Editor: Guang Zhu

Copyright (C) 2015 Shanmugavel Chinnathambi et al. This is an open access article distributed under the Creative Commons Attribution License, which permits unrestricted use, distribution, and reproduction in any medium, provided the original work is properly cited.

\begin{abstract}
The interaction of antimetabolite 5-fluorouracil (5FU) with bovine serum albumin (BSA) under UVC (253.7 nm) irradiation was investigated in the present study using UV-Vis spectroscopy, steady state/time resolved fluorescence spectroscopic techniques. The stability of protein was found to be very strong when BSA gets bind to 5FU and moreover it is compared with the free BSA under UVC irradiation. From the fluorescence spectroscopic study, the stability of the complex was found to acquire 2-fold stronger than free protein. From the molecular modelling studies, we came to know the hydrogen bonds between BSA and antimetabolite 5FU are strong, up to $70.4 \mathrm{~J} / \mathrm{m}^{2}$ under UVC irradiation.
\end{abstract}

\section{Introduction}

Several examples of UVB (315-280 nm) and UVA (400$315 \mathrm{~nm}$ ) radiation which have induced biological effects on animals and human beings were established $[1,2]$. Changes in the serum level of sialoglycoproteins in mice which was under UVB radiation have been studied by Yamamoto et al. [3]. The release of haemoglobin under UVB radiation on human erythrocytes and the UVB dose-dependent conversion of haemoglobin to methaemogobin which was assessed in vitro has been studied by Misra et al. [4]. Several effects may occur for the protein under UV irradiation such as fragmentation, cross-linking, structural changes, aggregation, and oxidation by means of radical generation in the radiolysis of water [59].

Although solar UVC is absorbed by ozone layer in the stratosphere, its relevance to the biological system is limited.
Nowadays, growing interests have been observed in the area of UVC activated process. UVC based treatments are suitable for inactivation of viruses in therapeutic proteins derived from the plasma [10-13]. It is desired to inactivate the viruses without damaging the proteins.

Unknown viral contamination of serums and biological products has caused many problems in blood transfusion organizations and viral diagnostic laboratories. The most common virus found in fetal bovine serum (FBS) is bovine viral diarrhea virus (BVDV) [14]. A variety of methods have been used to remove the contaminating viruses from the blood components such as chromatography, heating, ionizing radiation, and nonionizing radiation like continuous or pulsed UV [15-17]. Recently, many studies have been carried out to investigate the interaction of serum albumin with small molecules, nanoparticles under UVC irradiation [18-22]. 
Bian et al. 2006 have reported on the interaction of artemisinin with BSA under UVC exposure in their work. This complex was irradiated in air at room temperature using UVC with single exposure dose of $0.3 \times 10^{3} \mu \mathrm{Wb} \mathrm{cm}^{-2}$. The decrease in binding constant indicates the artemisinin binding to BSA and this may be due to the presence of enough common ions and UVC exposure [18].

In 2007, Dong et al. have studied the interaction of Co (II) with BSA under UVC irradiation under physiological conditions. The results from this study furnished information on the changes in the environments of aromatic residues as the irradiating time was prolonged. Further adding of Co (II) to the irradiated BSA solution brings a decrease in the value of binding constants and when the Co (II)-BSA mixture was exposed to irradiation the association constants get increased [19].

Michnik et al. demonstrated the influence of UVC$254 \mathrm{~nm}$ radiation with the spectroscopic and colorimetric properties of HSA in aqueous solution [20]. This radiation not only accelerated the aging of albumin but also caused other qualitative changes. The aim of the study was to compare the effect of $254 \mathrm{~nm}$ irradiation on the defatted albumin and albumin containing endogenous fatty acids. Two major wavelength points have been focused in the above said experiment. $254 \mathrm{~nm}$ is the first one which exerts the significant influence on the structural stability of HSA. Second, the difference in response to UVC irradiation existed between nondefated and fatty acid-free albumins.

Zuorro and Lavecchia have reported on the potential of nicotinic acid, a vitamin B3 compound with antioxidant activity in order to prevent the human albumin from damage when exposed to $254 \mathrm{~nm}$ irradiation [21]. The irradiance level in the range of $3.5-15 \mathrm{Wm}^{-2}$ and time applied between 5 and 30 minutes demonstrated that albumin undergoes rapid dose-dependent aggregation when subjected to irradiation. Addition of $0.2 \mathrm{mMNiAc}$ to the albumin solution reduced the damage causing to BSA. Production provided by NiAc was effective up to the radiation doses of about $30 \mathrm{kJm}^{-2}$, which is normally higher than the required dose for complete microbial and viral inactivation. Recently, the interaction of CS$\mathrm{Fe}_{3} \mathrm{O}_{4} @ \mathrm{ZnS}: \mathrm{Mn} / \mathrm{ZnS}$ nanoparticles with BSA and damage caused to BSA by these nanoparticles under UV irradiation has been observed by Liu et al. [22].

In our previous work, the binding studies of BSA under normal physiological conditions were reported recently [23]. The present work deals with the interaction of 5FU with BSA under UVC (253.7 nm) irradiation under physiological conditions and the binding stability of 5FU with BSA was checked using UV-Vis, steady/excited state fluorescence spectroscopy techniques; further these data were discussed with molecular modeling results. Additionally, the potential of 5FU which has the antimetabolite activity was investigated in order to know whether this activity has the ability to protect BSA from the damage against UVC irradiation.

\section{Materials and Methods}

2.1. Materials. Bovine serum albumin was purchased from Hi Media laboratory Pvt. Limited, Mumbai, India, and it was used without any further purification. Millipore water was used for preparing solution throughout the experiments. BSA solution was prepared in Tris- $\mathrm{HCl}$ buffer solution of $\mathrm{pH} 7.4$ and kept in the dark condition at $4^{\circ}$ C. 5-Fluorouracil ( $\left.\geq 99 \%\right)$ was purchased from Celon Laboratories Ltd., Hyderabad, India. The stock solution for 5FU was also prepared using the same buffer. Concentration ratio of drug $(1 \mu \mathrm{M})$ : protein $(1 \mu \mathrm{M})$ was used throughout the experiments.

2.2. Methods. Absorption spectra were recorded using UV-Visible absorption spectrophotometer (Perkin-Elmer Lamda35, Waltham, MA). The steady state fluorescence emission measurements were made using a spectrofluorometer (Fluoromax-2, ISA; Jobin-Yvon-Spex, Edison, NJ) and spectral band pass was kept as $5 \mathrm{~nm}$ for both excitation and emission monochromators. The emission spectrum was recorded at $280 \mathrm{~nm}$ excitation. Synchronous fluorescence spectra were recorded by simultaneously scanning the excitation $\left(\lambda_{\mathrm{ex}}\right)$ and emission $\left(\lambda_{\text {em }}\right)$ monochromators with two different constant wavelength intervals $(\Delta \lambda=60 \mathrm{~nm})$ between the excitation and emission monochromators. Fluoromax-2 equipped with excitation source ( $150 \mathrm{~W}$ ozone free xenon arc lamp) coupled to the monochromator delivers light to the sample at a desired wavelength and the fluorescence emission from the sample is collected by an emission monochromator to a photomultiplier tube (R928; Hamamatsu, Shizuoka-Ken, Japan). In addition, using the absorption spectrum of $5 \mathrm{FU}$ and fluorescence spectrum of BSA the fluorescence resonance energy transfer was evaluated.

Lifetime measurements were made using Time Correlated Single Photon Counting System (TCSPC, Horiba Jobin Yuvon IBH, UK) with a fast response red sensitive PMT (Hamamatsu Photonics, Japan) detector. The excitation source used in the experiment was a light emitting diode laser of wavelength $280 \mathrm{~nm}$ (pulse width $<0.1 \mathrm{~ns}$ ) and the decay measurements were made at $350 \mathrm{~nm}$. The fluorescence emission was collected at 90 degree from the path of the light source. The electrical signal was amplified by a TB02 pulse amplifier (Horiba) fed to the constant fraction discriminator (CFD, Phillips, Netherlands). The first detected photon was used as a start signal by a time-to-amplitude converter (TAC), and the excitation pulse triggers the stop signal. The multichannel analyzer (MCA) records repetitive start-stop signals from the TAC and generates a histogram of photons as a function of time-calibrated channels. The instrument response function was obtained using a Rayleigh scatter of Ludox-40 (40 wt.\% suspension in water; SigmaAldrich) in a quartz cuvette at $280 \mathrm{~nm}$ excitation. Decay analysis software (DAS6 V6.0, Horiba) was used to extract the lifetime components. The goodness of fit was judged by chi-square values as well as by the visual observations of fitted line and residuals. Each fluorescence decay was analyzed with two and three lifetimes and then values of $\chi^{2}$ were compared to determine the best fit. The time calibration of the system was $2.7844 \times 10^{-11} \mathrm{sec} / \mathrm{ch}$.

The solutions of BSA and 5FU-BSA were irradiated in air at room temperature using photoreactor (Germicidal 15T/8General Electric, Fair-field, CT) for different time intervals 


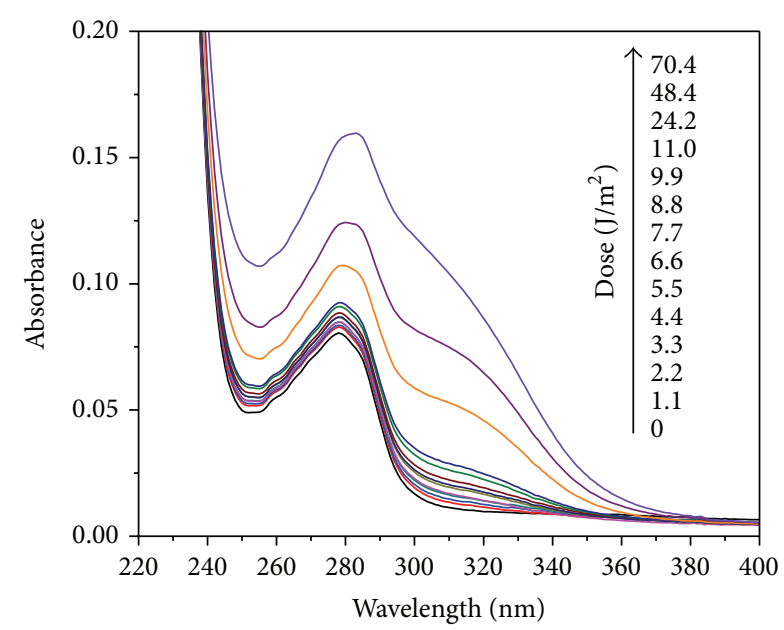

(a)

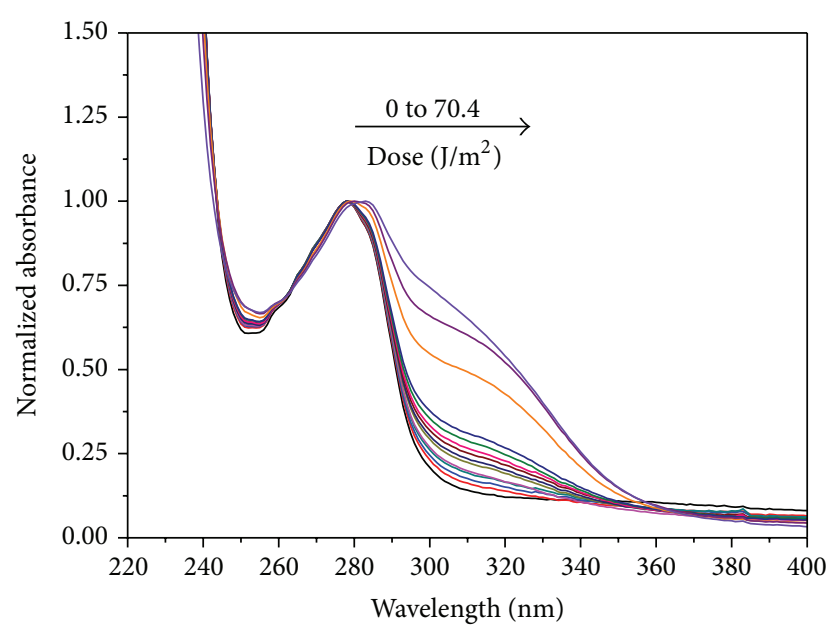

(b)

FIGURE 1: (a) Ultraviolet-Visible absorption spectra of BSA under UVC irradiation. (b) Normalized spectra. Irradiation time is 0-640 seconds.

with a distance of $10 \mathrm{~cm}$ from the light source. The intensity of radiation used was $11 \mu \mathrm{W} / \mathrm{cm}^{-2}$. The BSA and 5FU-BSA solutions (in the molar ratio $1: 1$ ) were exposed to UVC at 0 $70.4 \mathrm{~J} / \mathrm{m}^{2}$. The corresponding UV-Vis spectra were measured and the unexposed 5FU-BSA solution was used for reference.

\section{Results and Discussion}

3.1. UV-Visible Absorption Spectroscopic Characterization under UVC Irradiation. The influence of UVC $(253.7 \mathrm{~nm})$ irradiation on BSA and 5FU-BSA complex in aqueous solutions was studied by the absorption properties using UV-Vis spectroscopy. The dose-dependent effect and conformational restructuring of albumin was monitored for higher dose range $\left(0\right.$ to $\left.70.4 \mathrm{~J} / \mathrm{m}^{2}\right)$. In our previous work, we have reported the binding equilibrium studies and subsequent effect for the interaction between 5FU and BSA under normal conditions [24].

The 5FU-BSA complex (in molar ratio 1:1) solution was kept under UVC exposure in air at room temperature for different time intervals of $0-640$ seconds $\left(0-70 \mathrm{~J} / \mathrm{m}^{2}\right)$. The corresponding UV-Vis spectra were taken for the UVC treated and untreated solutions. From Figure 1(a) the absorbency of BSA was found to increase for prolonged exposure of time. The characteristics peak of BSA showed hyperchromic effect with red shift (Figure 1(b)) and expressed some orderly changes. As the free BSA alone when gets treated with UVC irradiation, increase in the absorbance between 300 and $340 \mathrm{~nm}$ and two peaks located at $255 \mathrm{~nm}$ (local minimum) and $278 \mathrm{~nm}$ (local maximum) was observed. The ratio between the local maximum and local minimum $\left(A_{\max } / A_{\min }\right)$ was chosen by Artyukhov et al. to monitor the structural changes induced by UVC irradiation to the BSA molecules [5]. The increase in absorbance was observed between 300 and $340 \mathrm{~nm}$ which reflects the formation of BSA aggregates following protein denaturation. These results indicate that the aromatic residue environment has induced some changes for the prolonged time of irradiation. Under such conditions in the present study, we came to know that $A_{\max } / A_{\min }$ was essentially dependent on the dose of irradiation applied and photochemical alteration may occur in the aromatic amino acid residues of BSA.

We have tested at all irradiance levels and observed a progressive increase in absorbance in the region between 300 and $340 \mathrm{~nm}$ region with respect to exposure time, indicating that UVC irradiation makes the BSA molecules to aggregate. Hence, to quantify the extent of protein damage, we used the following parameter: $\alpha=A_{320}^{*}-A_{320}$, where $A_{320}^{*}$ and $A_{320}$ are the absorbance's at $\lambda=320 \mathrm{~nm}$ of the UVC treated and untreated BSA, respectively. $\alpha$ is the difference in absorbance between $280 \mathrm{~nm}$ and $320 \mathrm{~nm}$ of the UVC treated and untreated BSA.

The effects of UVC exposure time and irradiance level $\alpha$ are illustrated in Figure 3. These two plots reveal some important points. First, an increase in irradiance time causes an increase in $\alpha$ value even in the absence and presence of 5FU. Secondly, at each irradiance level, 5FU made protective effect on BSA. Finally, in the absence of 5FU, $\alpha$ value was found to get increased for both the absorption maximum ( 280 and $320 \mathrm{~nm}$ ) values with respect to the exposure time which is shown in Figure 3(a). Similarly, in the absence of the 5FU, the time dependence of $\alpha$ is better described by second order polynomial. But $\alpha$ value showed an increase at $320 \mathrm{~nm}$ and decrease at $280 \mathrm{~nm}$ with increasing time of UVC irradiation in the presence of 5FU with BSA (Figure 3(b)).

For the BSA-5FU complex, the absorption maximum $(280 \mathrm{~nm})$ gets decreased for increase in 5FU concentration. After continuous UVC irradiation of about $70.4 \mathrm{~J} / \mathrm{m}^{2}$ on the BSA-5FU complex, two peaks in the absorption spectrum got breached (Figures 2(a) and 2(b)). Therefore, very strong bonding was achieved for the BSA5FU complex for continuous UVC irradiation of about $70.4 \mathrm{~J} / \mathrm{m}^{2}$. At the same time, an enhancement at $320 \mathrm{~nm}$ in the absorption spectrum was noticed under UVC irradiation which occurred due to the protein aggregation. 


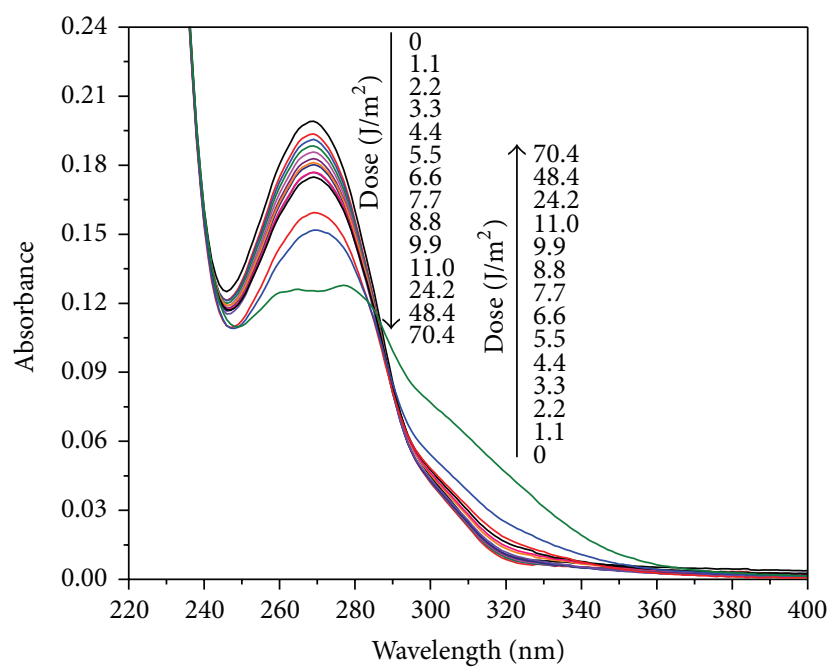

(a)

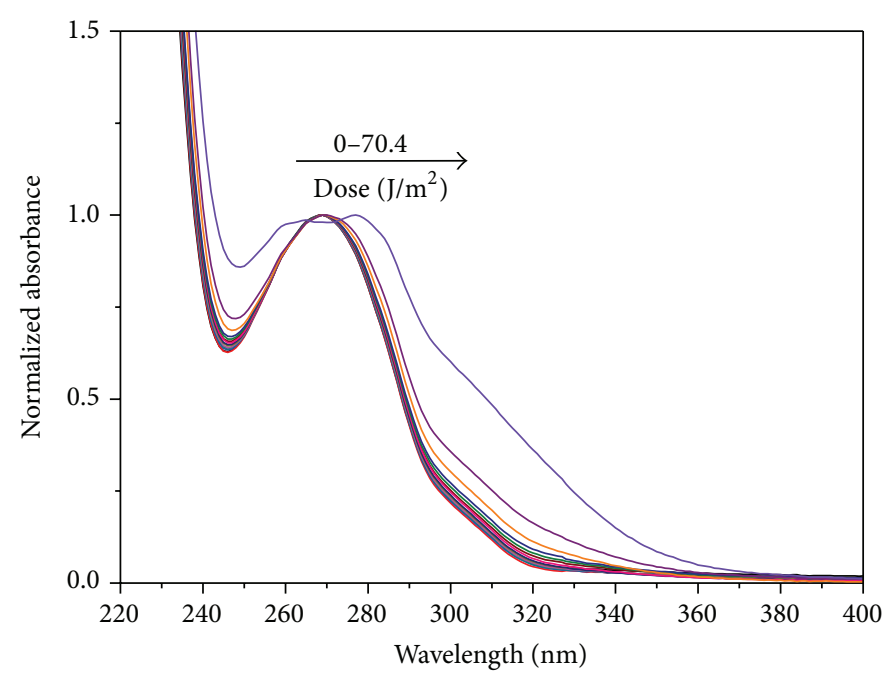

(b)

FIgURE 2: (a) Ultraviolet-Visible absorption spectra of BSA complex with 5FU under UVC irradiation. (b) Normalized spectra. Irradiation time is $0-640$ seconds.

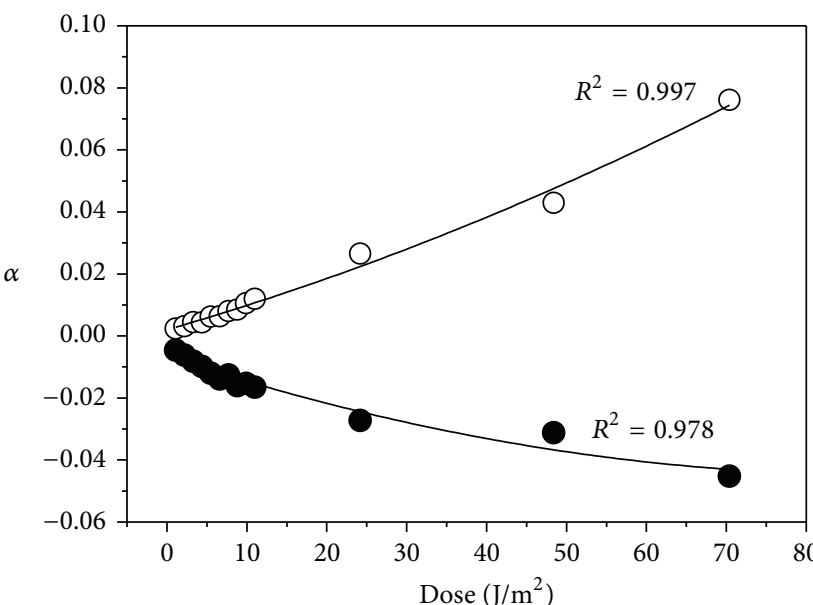

- $280 \mathrm{~nm}$

○ $320 \mathrm{~nm}$

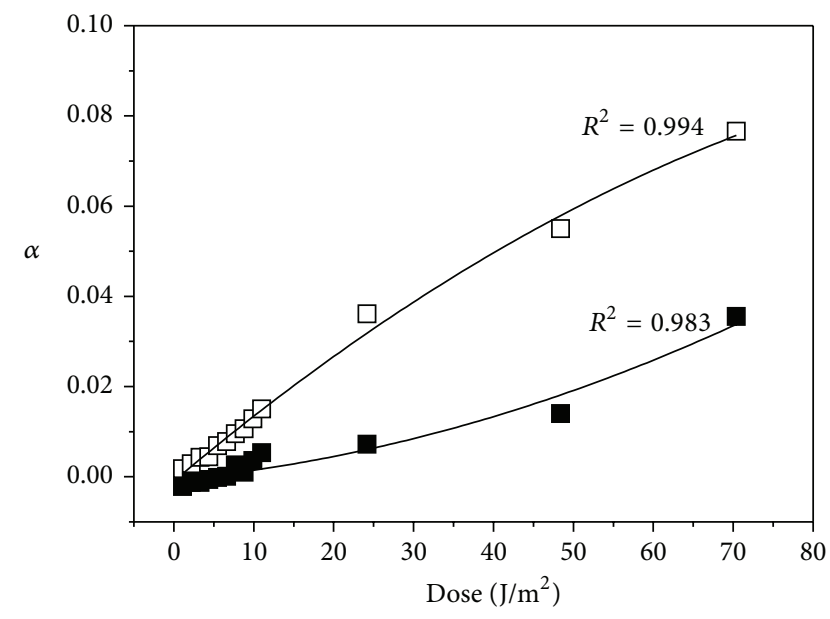

$280 \mathrm{~nm}$

- $320 \mathrm{~nm}$

(a)

(b)

FIGURE 3: Effect of UVC radiation dose on BSA in the absence and presence of 5FU. $\alpha$ is the difference between the absorbance's at $280 \mathrm{~nm}$ (a) and $320 \mathrm{~nm}$ (b) of irradiated and unirradiated samples. The curves represent best fits to the corresponding data points.

3.2. Steady State Fluorescence Spectroscopic Study under UVC Irradiation. The changes in the fluorescence excitation, emission, and synchronous spectra for free BSA (Figures 4(a), 4(b), and 4(c)) and BSA with 5FU (Figures 4(d), 4(e), and $4(\mathrm{f})$ ) are shown in Figure 4 as a function of UVC light dose, respectively. A decrease in the intensities of excitation, emission, and synchronous maxima was observed for increase in UVC light dose. However, the decrease in the intensity observed was very minimal for BSA-5FU complex and this gets saturated for UVC dose higher than $11 \mathrm{~J} / \mathrm{m}^{2}$. Figures $4(\mathrm{~g}), 4(\mathrm{~h})$, and $4(\mathrm{i})$ show difference in the fluorescence excitation, emission, and synchronous intensity between the control and UVC irradiated sample for both BSA and BSA-5FU complex, respectively. The fluorescence excitation $\left(\Delta F_{\mathrm{ex}}\right)$, emission $\left(\Delta F_{\mathrm{em}}\right)$, and synchronous $\left(\Delta F_{\mathrm{SLS}}\right)$ intensity difference between control and UVC treated sample was calculated using the following equation:

$$
\Delta F_{\mathrm{ex}}=\Delta F_{\mathrm{em}}=\Delta F_{\mathrm{SLS}}=\left(F_{0}-F\right),
$$

where $F_{0}=$ fluorescence intensity of control. $F=$ fluorescence intensity of irradiated samples.

From Figures 4(g), 4(h), and 4(i) it is observed that the change in the value $\Delta F$ is more for free BSA than that of BSA5FU complex. For example, at a dose of $24 \mathrm{~J} / \mathrm{m}^{2}$, the changes 


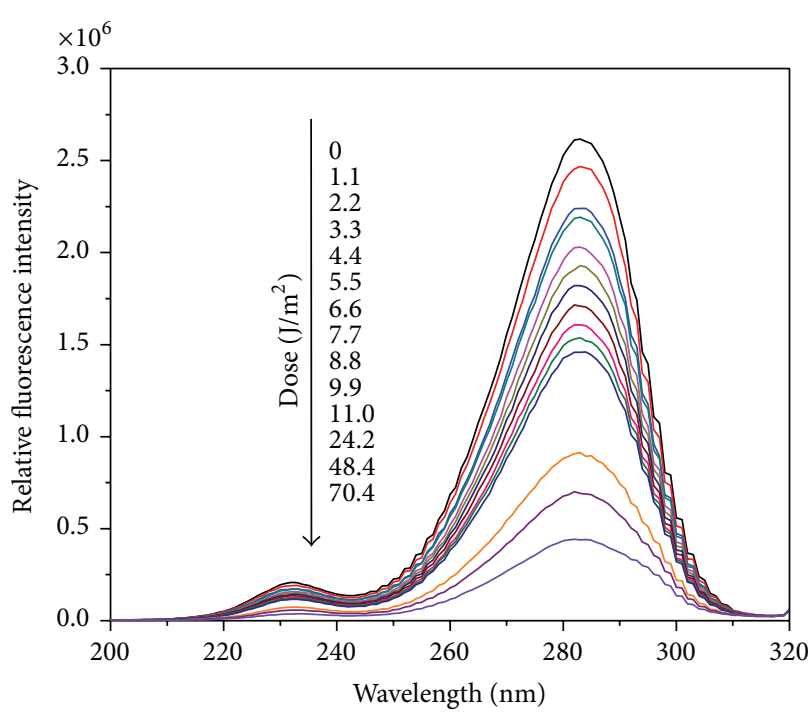

(a)

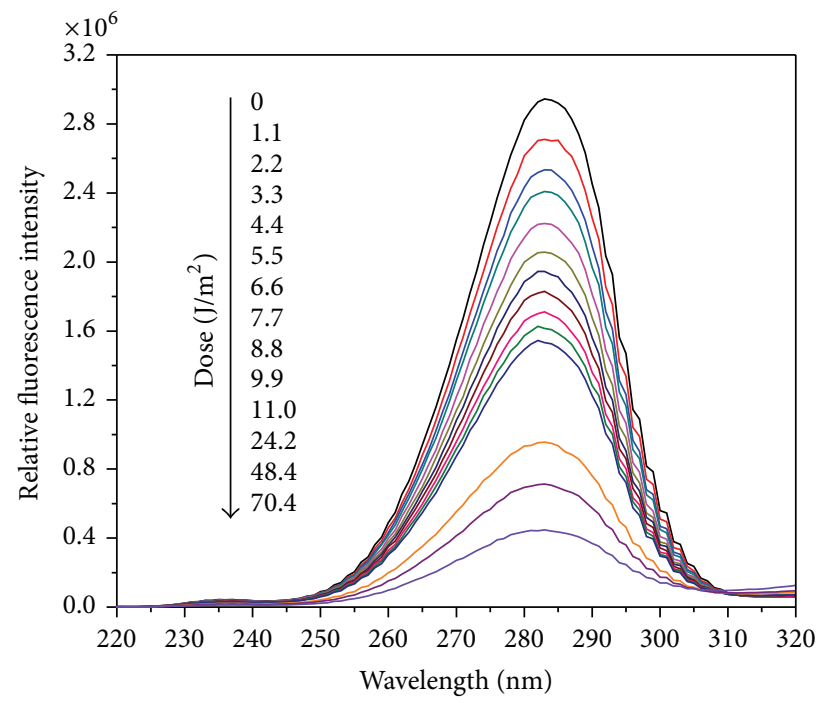

(c)

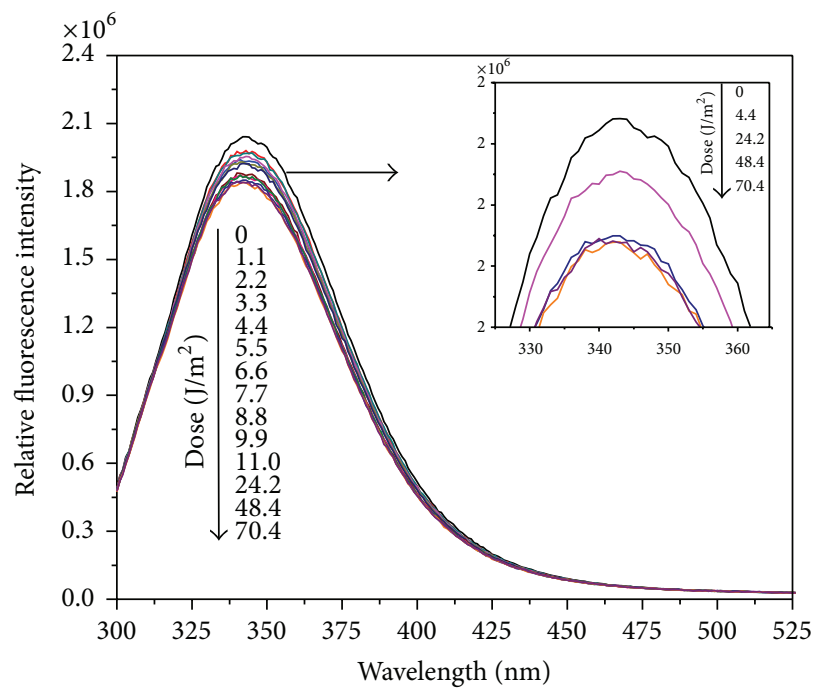

(e)

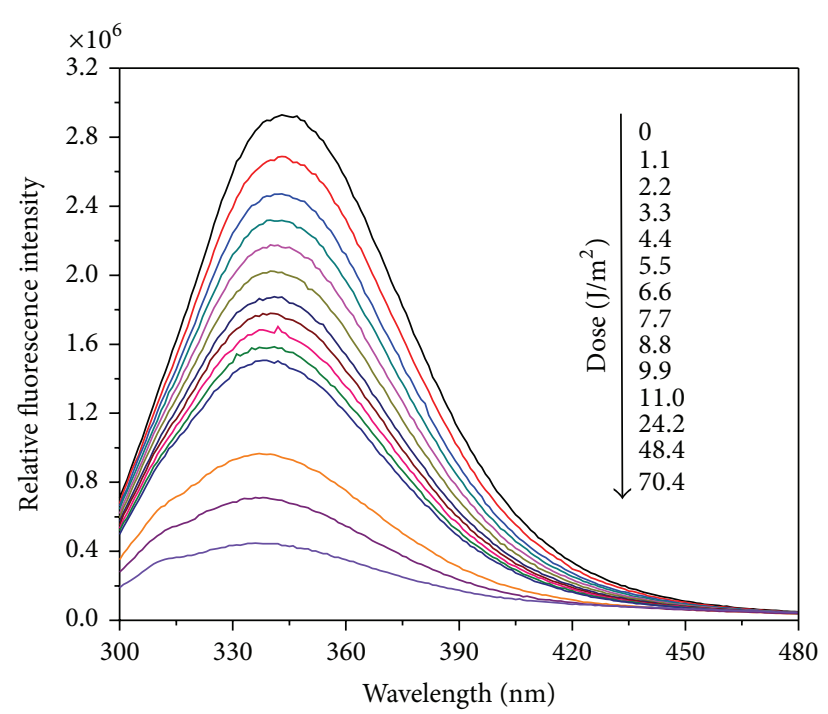

(b)

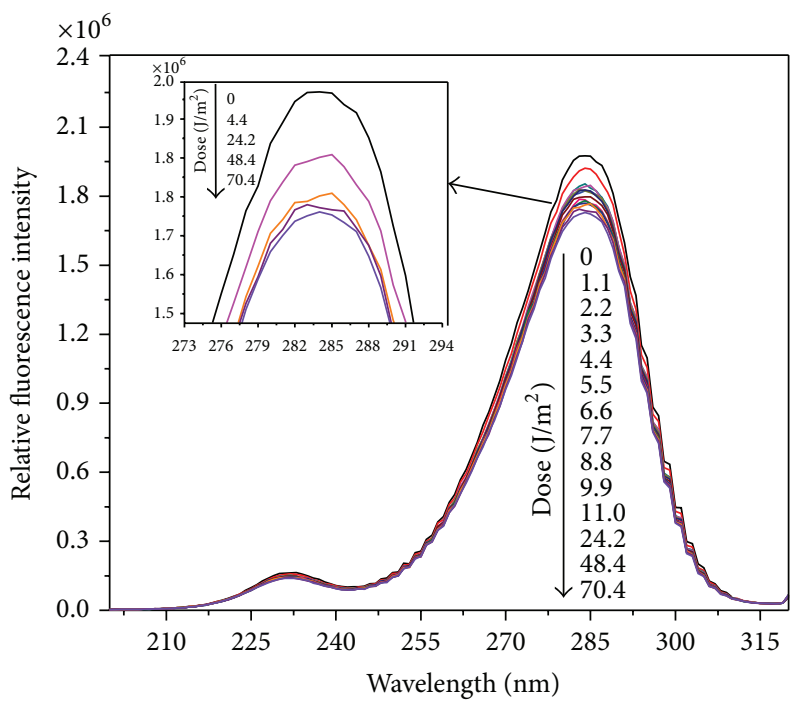

(d)

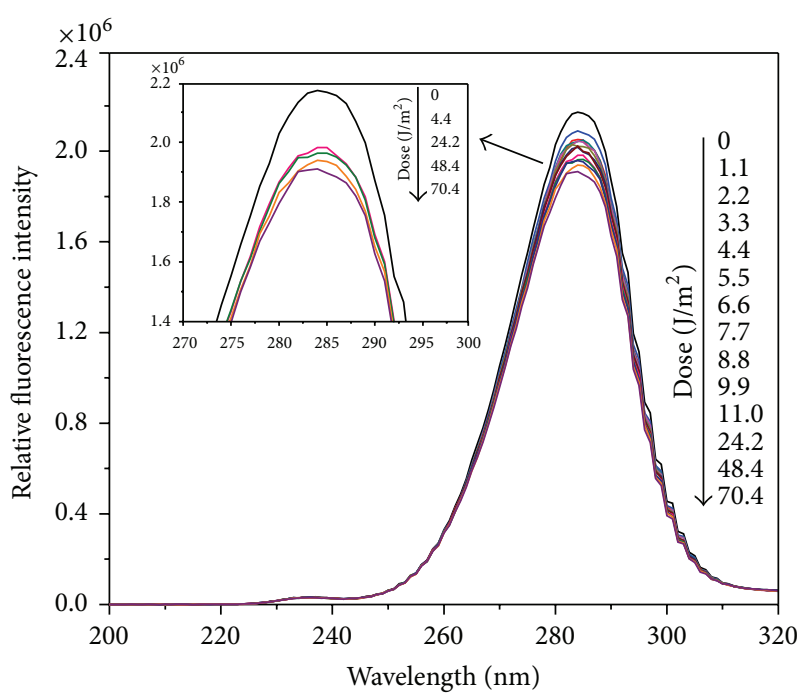

(f)

Figure 4: Continued. 


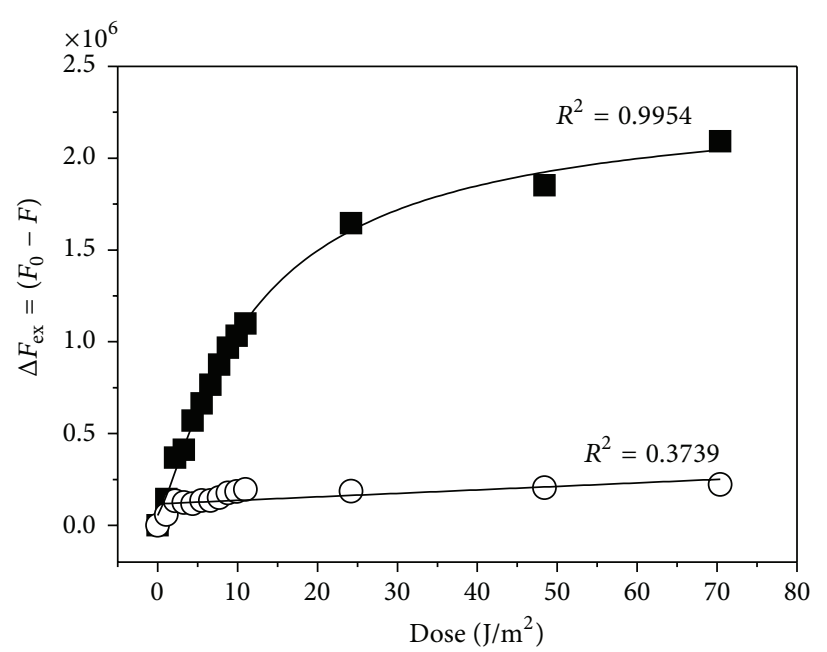

(g)

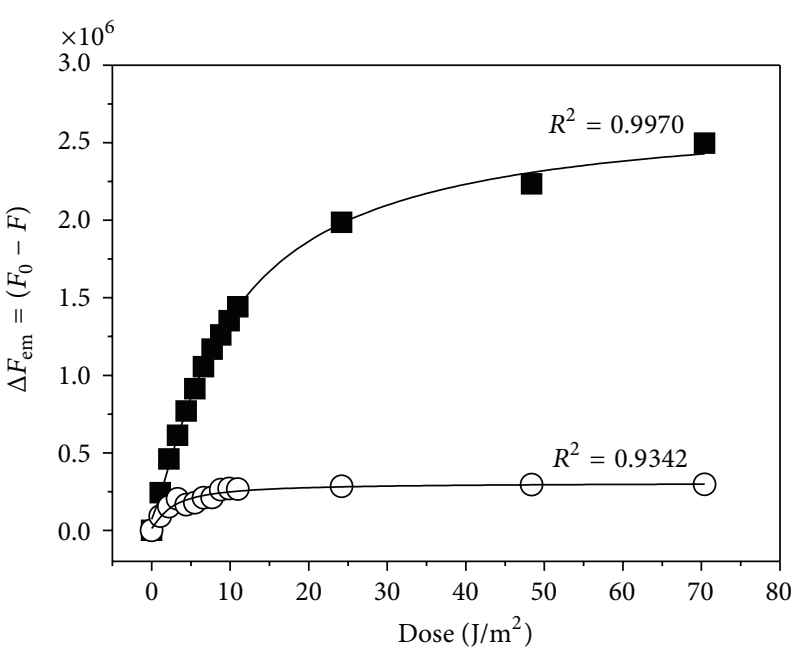

(h)

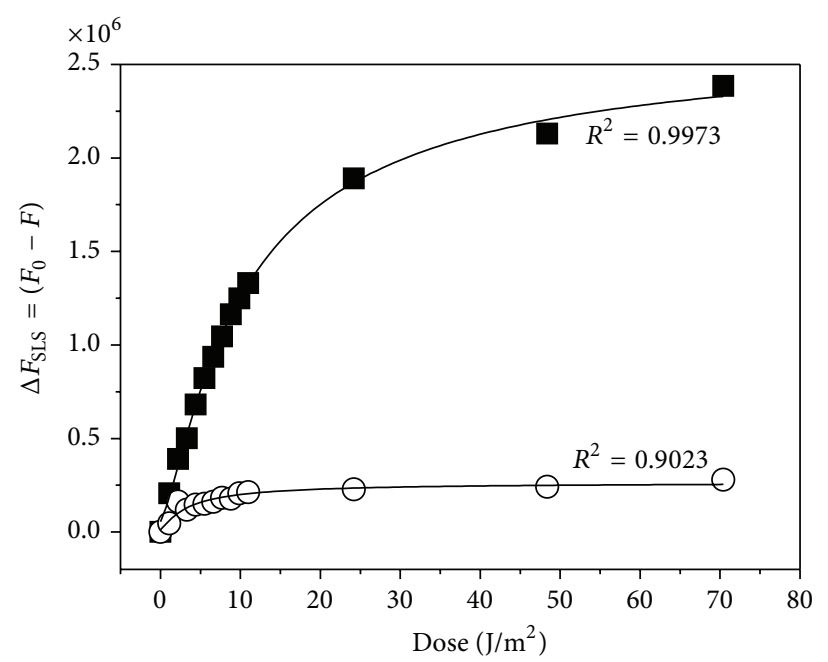

- BSA

$\circ \mathrm{BSA}+5 \mathrm{FU}$

(i)

Figure 4: Fluorescence excitation, emission, and synchronous spectra of BSA ((a), (b), and (c)) and complex with 5FU ((d), (e), and (f)) under different time of UVC irradiation. Difference of BSA and complex with 5FU under increasing time of UVC irradiation ((g), (h), and (i)).

observed in the intensities were 1.92-fold for excitation, 1.91fold for emission, and 2.06-fold for synchronous. The change in $\Delta F_{\text {ex }}, \Delta F_{\text {em }}$, and $\Delta F_{\text {SLS }}$ values was noticed for the doses up to $24 \mathrm{~J} / \mathrm{m}^{2}$ from this analysis and above $24 \mathrm{~J} / \mathrm{m}^{2}$ the increase in intensity attained saturation. On the other hand, BSA with 5FU does not show any marginal changes in the $\Delta F_{\mathrm{ex}}, \Delta F_{\mathrm{em}}$, and $\Delta F_{\text {SLS }}$ values even at higher doses $\left(70.4 \mathrm{~J} / \mathrm{m}^{2}\right)$.

\subsection{Time Resolved Fluorescence Spectroscopic Characteriza-} tion under UVC Irradiation. Figures 5(a) and 5(b) show the fluorescence decay characterization of BSA and BSA-5FU complex which was carried out at room temperature under UVC irradiation. The data reveals that there is a significant change in the lifetime values when plotted as a function of light dose. At a first glance the decay in control exhibits a markedly less pronounced curvature in the logarithmic plot compared with the treated samples. The shape of these curves brings two interesting fact: (i) the fluorescence decay has a multiphase nature with more than two lifetime components and (ii) UVC irradiation changes the exciton lifetime profile in such a way that it accelerates the fast phase and retards the slow decay components. A nonlinear least square reconvolution fitting of the data clearly shows that a model comprising triexponential relaxation provides a significantly better description of the decay than a biexponential model, which is evident from the corresponding $\chi^{2}$ values.

The mean lifetime reflecting the overall fluorescence decay strongly decreases with increasing UVC irradiation time. From Figure 5 it is observed that the BSA-5FU complex has long decay time as compared to free BSA. Figure 5(c) 


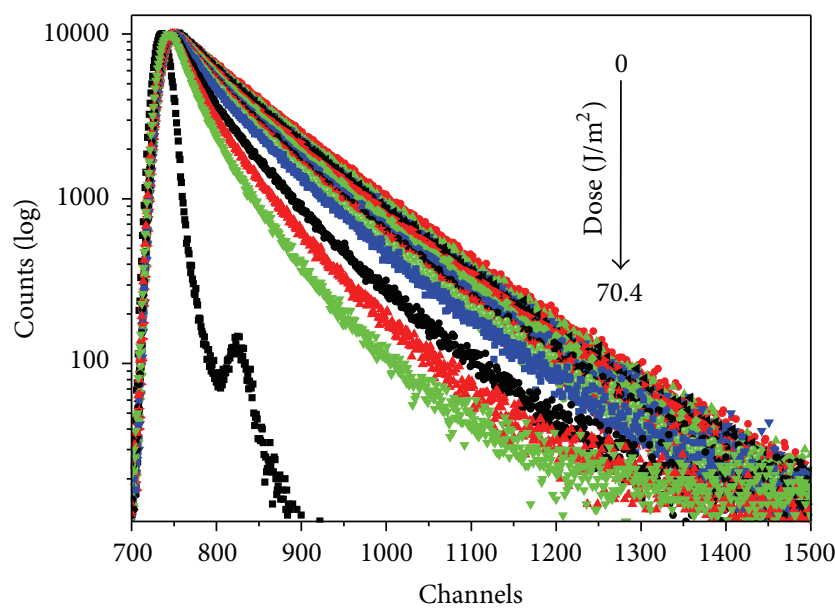

(a)

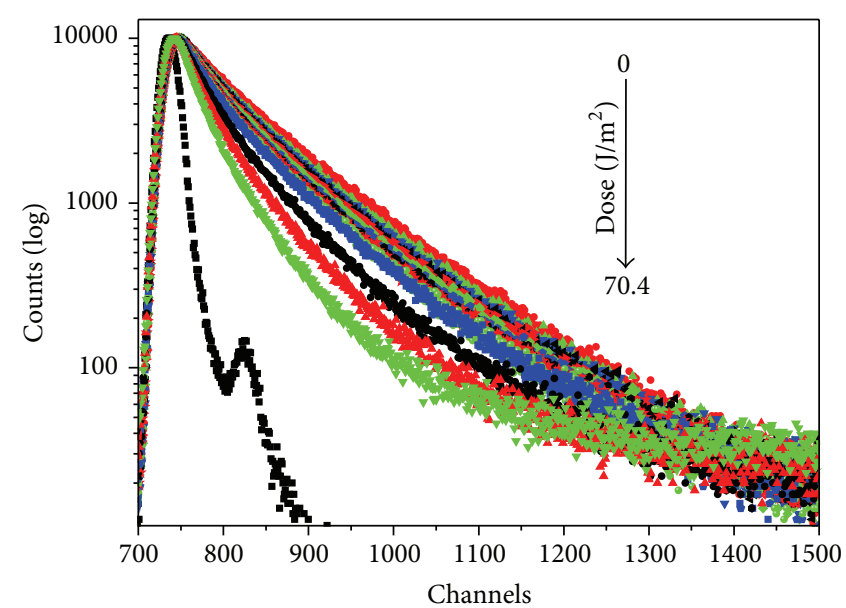

(b)

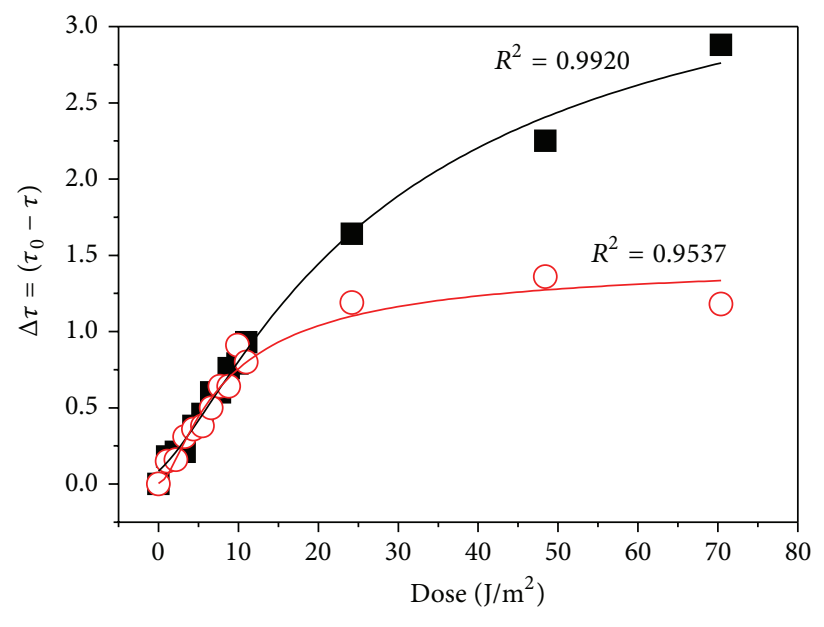

- BSA

$\mathrm{BSA}+5 \mathrm{FU}$

(c)

FIGURE 5: Fluorescence lifetime decay profile of BSA (a) and complex with 5FU (b) under UVC irradiation with increasing dose $\left(\mathrm{J} / \mathrm{m}^{2}\right)$. (c) Stern-Volmer plot represents the difference between stability of BSA and binding stability of BSA with 5FU under UVC irradiation with increasing time interval.

depicts the difference between the free BSA and complex lifetime variation that depends upon the UVC irradiation time. At $70.4 \mathrm{~J} / \mathrm{m}^{2}$ the complex expressed a long lifetime than free BSA.

The lifetime difference $(\Delta \tau)$ between control and irradiated sample was calculated using the following equation:

$$
\Delta \tau=\left(\tau_{0}-\tau\right),
$$

where $\tau_{0}=$ lifetime of control. $\tau=$ lifetime of irradiated samples.

The data in Tables 1 and 2 evidently indicates that the UVC irradiation on the samples affects the three resolved decay components $\left(\tau_{1}, \tau_{2}\right.$, and $\left.\tau_{3}\right)$; simultaneously, the relative amplitudes of these components $\left(A_{1}, A_{2}\right.$, and $\left.A_{3}\right)$ decrease for the same. In the case of free BSA, all the slow, fast components and average lifetime with the order of ns slowed down to about $2.88 \mathrm{~ns}, 1.18 \mathrm{~ns}$ for BSA-5FU complex.
3.4. Calculation of Forster Radius $\left(R_{0}\right)$ from Spectral Overlap. According to the Forster dipole-dipole nonradiative energy transfer theory, energy transfer is feasible if the following conditions are satisfied $[25,26]$ : (i) the donor (fluorescence emission) having more fluorescence quantum yield, (ii) overlap ( $>30 \%)$ of the fluorescence emission spectrum of the donor with the absorption spectrum of the acceptor [24], and (iii) the distance between the donor and acceptor being within $8 \mathrm{~nm}$.

Energy transfer efficiency $(E)$ is defined by the following equation:

$$
E=1-\left(\frac{F}{F_{0}}\right),
$$

where $F$ is the fluorescence intensity of the donor in the presence of acceptor and $F_{0}$ is the fluorescence intensity of the donor. 
TABLE 1: Exited state decay profile of BSA under UVC irradiation.

\begin{tabular}{|c|c|c|c|c|c|c|c|c|}
\hline Dose $\left(\mathrm{J} / \mathrm{m}^{2}\right)$ & $\tau_{1}(\mathrm{~ns})$ & $\tau_{2}(\mathrm{~ns})$ & $\tau_{3}(\mathrm{~ns})$ & $\alpha_{1}$ & $\alpha_{2}$ & $\alpha_{3}$ & $\tau_{0}$ & $\chi^{2}$ \\
\hline 0 & $5.11 \pm 1.60$ & $2.81 \pm 0.25$ & $6.82 \pm 0.09$ & 15.44 & 18.15 & 66.41 & 6.23 & 1.14 \\
\hline 1.1 & $3.77 \pm 2.48$ & $2.59 \pm 0.44$ & $6.45 \pm 0.05$ & 16.28 & 6.17 & 77.54 & 6.05 & 1.18 \\
\hline 2.2 & $5.21 \pm 0.45$ & $2.32 \pm 0.12$ & $6.97 \pm 0.12$ & 36.15 & 17.60 & 46.24 & 6.02 & 1.12 \\
\hline 3.3 & $5.05 \pm 0.34$ & $2.09 \pm 0.08$ & $7.20 \pm 0.10$ & 43.96 & 15.51 & 40.52 & 6.02 & 1.08 \\
\hline 4.4 & $3.44 \pm 1.33$ & $2.03 \pm 0.15$ & $6.33 \pm 0.03$ & 11.16 & 16.12 & 72.72 & 5.85 & 1.09 \\
\hline 5.5 & $3.73 \pm 1.10$ & $1.87 \pm 0.10$ & $6.46 \pm 0.04$ & 20.52 & 16.48 & 63.00 & 5.77 & 1.06 \\
\hline 6.6 & $4.33 \pm 0.66$ & $1.80 \pm 0.06$ & $6.79 \pm 0.07$ & 33.77 & 19.40 & 46.83 & 5.63 & 1.01 \\
\hline 7.7 & $3.39 \pm 0.63$ & $1.38 \pm 0.07$ & $6.60 \pm 0.04$ & 34.47 & 12.54 & 52.99 & 5.63 & 1.08 \\
\hline 8.8 & $3.26 \pm 0.55$ & $1.56 \pm 0.07$ & $6.25 \pm 0.05$ & 24.13 & 17.82 & 58.05 & 5.47 & 1.07 \\
\hline 9.9 & $3.21 \pm 0.39$ & $1.39 \pm 0.06$ & $6.34 \pm 0.04$ & 30.27 & 15.74 & 53.99 & 5.44 & 1.06 \\
\hline 11.0 & $3.02 \pm 0.26$ & $1.23 \pm 0.05$ & $6.32 \pm 0.04$ & 35.07 & 15.12 & 49.81 & 5.30 & 1.08 \\
\hline 24.2 & $2.31 \pm 0.05$ & $0.82 \pm 0.09$ & $5.80 \pm 0.03$ & 46.74 & 12.52 & 40.75 & 4.59 & 1.06 \\
\hline 48.4 & $1.89 \pm 0.04$ & $0.64 \pm 0.09$ & $5.15 \pm 0.03$ & 50.26 & 12.19 & 37.55 & 3.98 & 1.08 \\
\hline 70.4 & $1.60 \pm 0.02$ & $0.47 \pm 0.05$ & $4.65 \pm 0.03$ & 55.96 & 14.78 & 29.26 & 3.35 & 1.05 \\
\hline
\end{tabular}

TABLE 2: Exited state decay profile of BSA complex with 5FU under UVC irradiation.

\begin{tabular}{lcccccccc}
\hline Dose $\left(\mathrm{J} / \mathrm{m}^{2}\right)$ & $\tau_{1}(\mathrm{~ns})$ & $\tau_{2}(\mathrm{~ns})$ & $\tau_{3}(\mathrm{~ns})$ & $\alpha_{1}$ & $\alpha_{2}$ & $\alpha_{3}$ & $\tau_{0}$ & $\chi^{2}$ \\
\hline 0 & $4.62 \pm 1.13$ & $1.93 \pm 0.08$ & $6.78 \pm 0.08$ & 28.37 & 17.76 & 53.87 & 5.93 & 1.04 \\
1.1 & $3.86 \pm 0.74$ & $1.61 \pm 0.06$ & $6.75 \pm 0.05$ & 30.23 & 17.31 & 52.46 & 5.78 & 1.01 \\
2.2 & $3.55 \pm 0.38$ & $1.42 \pm 0.06$ & $6.85 \pm 0.04$ & 35.38 & 14.41 & 50.20 & 5.77 & 1.07 \\
3.3 & $3.21 \pm 0.42$ & $1.35 \pm 0.06$ & $6.61 \pm 0.04$ & 33.27 & 14.44 & 52.29 & 5.62 & 1.09 \\
4.4 & $3.18 \pm 0.42$ & $1.23 \pm 0.05$ & $6.63 \pm 0.04$ & 36.45 & 13.69 & 49.86 & 5.57 & 1.05 \\
5.5 & $3.82 \pm 0.39$ & $1.52 \pm 0.04$ & $7.02 \pm 0.07$ & 39.43 & 22.12 & 38.46 & 5.55 & 1.02 \\
6.6 & $3.10 \pm 0.35$ & $1.27 \pm 0.05$ & $6.61 \pm 0.05$ & 37.41 & 16.44 & 46.14 & 5.43 & 1.04 \\
7.7 & $2.59 \pm 0.35$ & $0.89 \pm 0.06$ & $6.31 \pm 0.03$ & 40.42 & 09.61 & 49.97 & 5.29 & 1.08 \\
8.8 & $3.06 \pm 0.32$ & $1.26 \pm 0.04$ & $6.57 \pm 0.05$ & 38.62 & 18.63 & 42.74 & 5.29 & 1.06 \\
9.9 & $2.00 \pm 0.07$ & $0.60 \pm 0.08$ & $5.81 \pm 0.02$ & 39.72 & 04.48 & 55.80 & 5.02 & 1.09 \\
11.0 & $3.22 \pm 0.29$ & $1.23 \pm 0.03$ & $6.61 \pm 0.06$ & 40.78 & 21.71 & 37.52 & 5.13 \\
24.2 & $2.09 \pm 0.04$ & $0.71 \pm 0.14$ & $5.66 \pm 0.03$ & 39.46 & 11.70 & 48.84 & 4.74 & 0.99 \\
48.4 & $1.77 \pm 0.02$ & $0.45 \pm 0.05$ & $5.21 \pm 0.04$ & 33.34 & 10.49 & 56.17 & 4.57 & 1.09 \\
70.4 & $1.71 \pm 0.03$ & $0.53 \pm 0.04$ & $5.26 \pm 0.07$ & 21.10 & 20.01 & 58.89 & 4.75 \\
\hline
\end{tabular}

The energy transfer efficiency can also be related to the critical energy transfer distance $\left(R_{0}\right)$. The critical energy transfer distance $R_{0}$ and the distance between the acceptor and donor can be evaluated using the following equation:

$$
E=\frac{R_{0}^{6}}{\left(R_{0}^{6}+r^{6}\right)},
$$

where $R_{0}$ is the critical distance when the transfer efficiency is $50 \%$ given by (4) and $r$ is the binding distance between the donor and acceptor:

$$
R_{0}=8.79 \times 10^{-25}\left[k^{2} N^{-4} \varphi_{D} J\right]
$$

where $k^{2}$ is the spatial orientation factor of the dipole. $N$ is the average refractive index of the water; $\varphi_{D}$ is the quantum yield of the donor in the absence of the acceptor. $J$ is the overlap integral of the fluorescence emission spectrum of the donor and the absorption spectrum of the acceptor in units $\mathrm{M}^{-1} \mathrm{~cm}^{3} . J$ is given by the following equation [27]:

$$
J(\lambda)=\int_{0}^{\infty} F_{D}(\lambda) \varepsilon_{A}(\lambda) \lambda^{4} d \lambda,
$$

where $F_{D}(\lambda)$ is the fluorescence intensity of the donor at wavelength $\lambda$ to $\lambda+\Delta \lambda$, with the total intensity normalized to unity and $\varepsilon_{A}(\lambda)$, the molar extinction coefficient of the acceptor at wavelength $(\lambda)$.

Figure 6 shows the schematic diagram of the fluorescence energy transfer and variation in the distance between donor and acceptor. The distance between the BSA and 5FU was calculated as $1.39 \mathrm{~nm}$ using (4) without UVC irradiation. After continuous UVC irradiation with $8.8 \mathrm{~J} / \mathrm{m}^{2}$, the " $r$ " value reaches $1.14 \mathrm{~nm}$. Finally, Forster distance again reaches around $1.35 \mathrm{~nm}$ after $70.4 \mathrm{~J} / \mathrm{m}^{2}$ of UVC irradiation (Table 3 ). This result was due to the following reasons:

(i) enhancement in the absorption spectrum after addition of $5 \mathrm{FU}$ to BSA solution, 


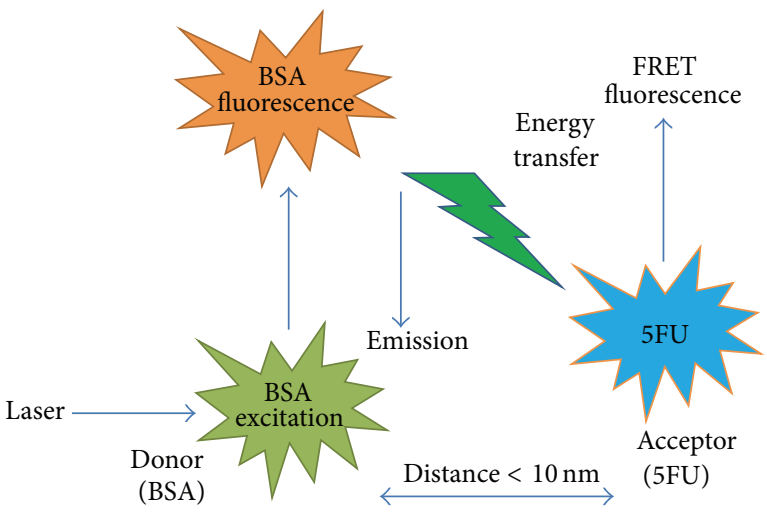

(a)

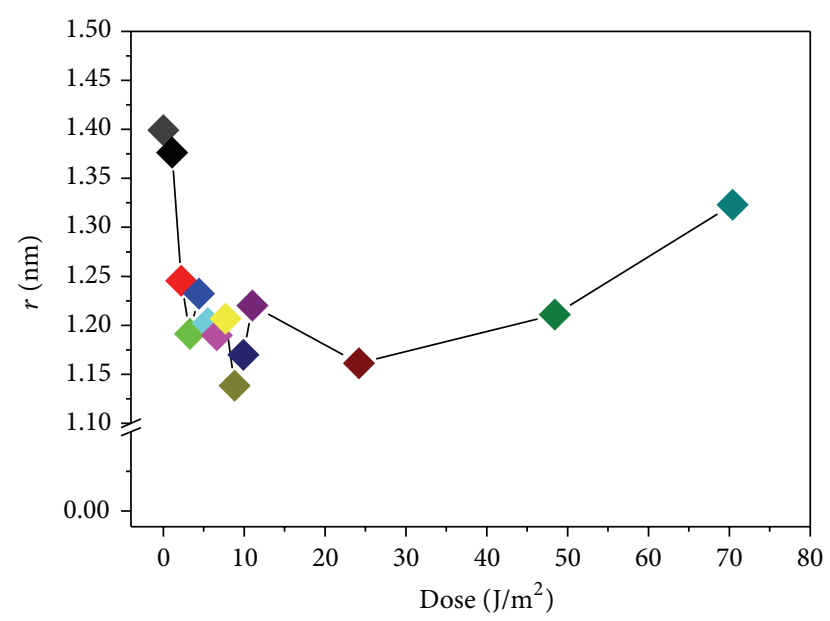

(b)

FIGURE 6: Changes between donor (BSA) and acceptor (5FU) distance ( $r$ ) due to different time of UVC irradiation at room temperature.

TABLE 3: Changes between donor (BSA) and acceptor (5FU) distance $(r)$ due to increasing dose of UVC irradiation.

\begin{tabular}{lccc}
\hline Dose $\left(\mathrm{J} / \mathrm{m}^{2}\right)$ & $R_{0} \times 10^{-10} \mathrm{~m}$ & $E=\left(1-F / F_{0}\right)$ & $r(\mathrm{~nm})$ \\
\hline 0 & 8.5475 & 0.0805 & 1.3992 \\
1.1 & 8.2379 & 0.0543 & 1.3762 \\
2.2 & 8.2631 & 0.0778 & 1.2454 \\
3.3 & 8.2328 & 0.0982 & 1.1914 \\
4.4 & 8.2196 & 0.0809 & 1.2324 \\
5.5 & 8.2280 & 0.0931 & 1.2024 \\
6.6 & 8.1683 & 0.1046 & 1.1899 \\
7.7 & 8.5290 & 0.1108 & 1.2068 \\
8.8 & 8.2195 & 0.1241 & 1.1384 \\
9.9 & 8.5795 & 0.1346 & 1.1699 \\
11.0 & 8.6843 & 0.1297 & 1.2201 \\
24.2 & 8.5865 & 0.1404 & 1.1614 \\
48.4 & 9.0619 & 0.1495 & 1.2108 \\
70.4 & 9.8949 & 0.1489 & 1.3231 \\
\hline
\end{tabular}

(ii) at the same condition, the fluorescence spectra showing quenching behavior,

(iii) the continuous variation in the overlap area between donor emission and acceptor absorption spectra.

Table 3 shows that the Forster distance variation depends upon the irradiation time and following factors: $R_{0}$ and $E$, where $k^{2}=2 / 3, N=1.33$, and $\varphi_{D}=0.15$. According to Valuer and Brochon the maximum academic value for $R_{0}$ should be $<10 \mathrm{~nm}$ and $r$ should be less than $8 \mathrm{~nm}$ [28]. In the present study both the $R_{0}$ and $r$ values are well within the permissible limit and these results indicate that there is a high probability for the energy transfer from BSA to 5FU to occur.

3.5. Molecular Modeling Study. X-ray crystal structures of bovine serum albumin (BSA) are taken from the protein data bank. Structures of BSA have been further subjected to docking studies using GLIDE Schrödinger suite USA 2009 software. Protein structure has been energy minimized using protein preparation wizard panel to add hydrogen; the charge state of protein residues is important for result generation by Glide. OPLS (Optimized Potential of Liquid Simulations) force field is used for minimization process. Protein preparation facility consists of two steps of preparation and refinement. Energy minimization reorients side-chain hydroxyl groups and alleviates potential steric clashes.

5-Fluorouracil (5FU) was the ligand taken for docking studies with BSA protein. Ligand structures were modeled using ACD/Chembasic. These structures were energyminimized using two algorithms, steepest descent and conjugate gradient. Compounds were docked in two crystal structures of BSA (3V03, 4F5S) using the Induced Fit Docking (IFD) panel. Here both the ligand and protein are flexible to dock, and hence many conformations were generated for an individual ligand. Based on the docking score, glide energy, and hydrogen bond interaction, the best conformation is sorted and results are analyzed.

The overall structure of BSA protein is helical with turns and extended loops and resembles "Y" shaped architecture. These two different proteins were individually docked with 5fluorouracil of both the binding sites. Glide energy, docking score, and hydrogen bond interaction of the ligands with key residues are given in Table 4. Docking results showed that both the ligands had good binding affinity in structure I (Figure 7) when being comparable with structure II (Figure 8). The energy obtained for structure II is low and hence binding of ligands in this domain is good. Docking scores of protein $(3 \mathrm{~V} 03,4 \mathrm{~F} 5 \mathrm{~S})$ and $5 \mathrm{FU}$ are comparable and the hydrogen bond interaction, hydrophobic residues are shown in Table 4. The results clearly indicate 5FU had strong binding with BSA through hydrogen bonding and hydrophobic force. 
TABLE 4: Glide energy, docking score, and hydrogen bond interaction of the ligands with key residues.

\begin{tabular}{|c|c|c|c|c|}
\hline Compounds & $\begin{array}{c}\text { Hydrogen bond } \\
\text { D-H } \cdots \text { A }\end{array}$ & Distance Å & Docking score $(\mathrm{kcal} / \mathrm{mol})$ & Glide energy $(\mathrm{kcal} / \mathrm{mol})$ \\
\hline $\begin{array}{l}\text { 5-FU } \\
\text { docked with } \\
3 \mathrm{~V} 03\end{array}$ & 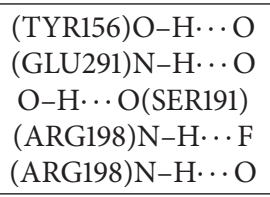 & $\begin{array}{l}2.84 \\
2.67 \\
3.00 \\
3.10 \\
2.90\end{array}$ & -4.15 & -29.22 \\
\hline $\begin{array}{l}\text { 5-FU } \\
\text { docked with } \\
4 \mathrm{~F} 5 \mathrm{~S}\end{array}$ & $\begin{array}{l}(\mathrm{TRP} 213) \mathrm{N}-\mathrm{H} \cdots \mathrm{F} \\
\mathrm{N}-\mathrm{H} \cdots \mathrm{O}(\mathrm{SER} 343) \\
(\mathrm{VAL} 342) \mathrm{N}-\mathrm{H} \cdots \mathrm{O} \\
(\mathrm{ARG} 217) \mathrm{N}-\mathrm{H} \cdots \mathrm{O}\end{array}$ & $\begin{array}{l}2.86 \\
2.92 \\
2.97 \\
3.11\end{array}$ & -6.18 & -27.73 \\
\hline
\end{tabular}

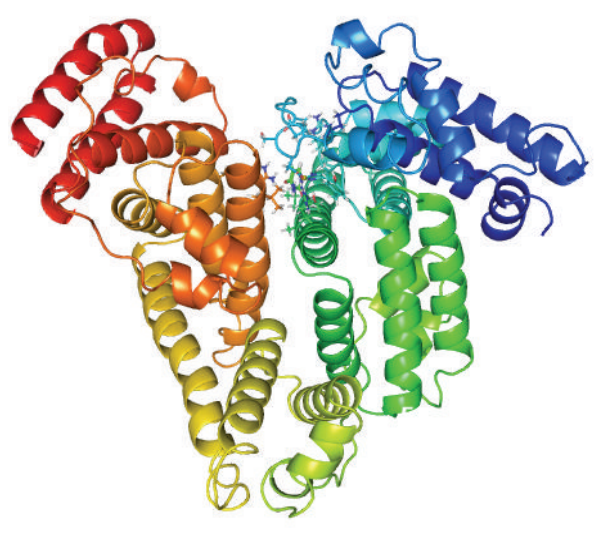

(a)

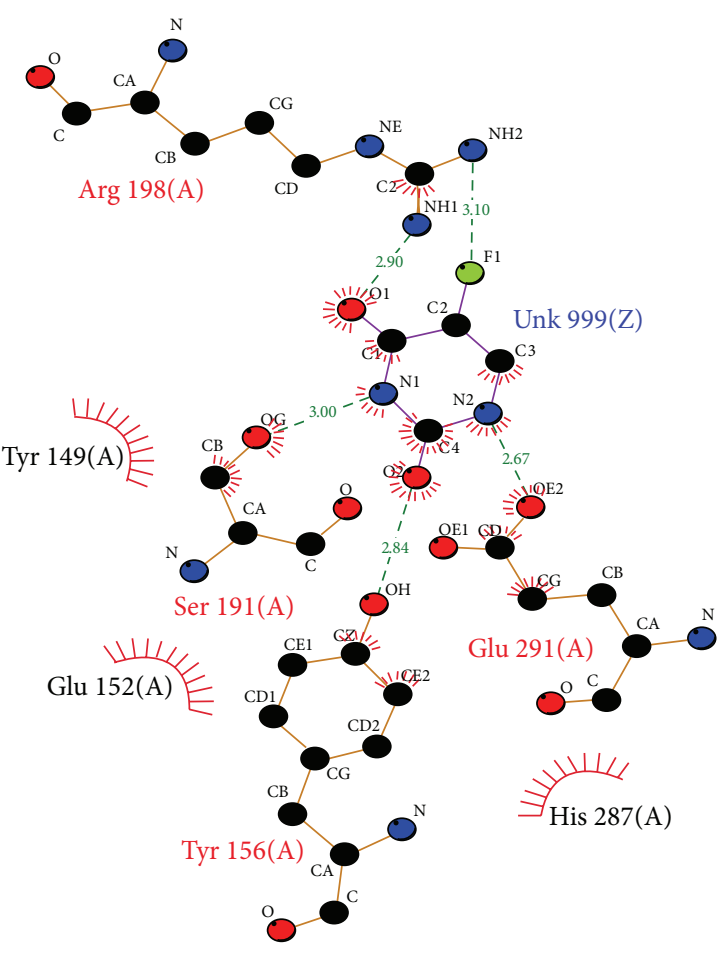

(b)

FIGURE 7: Bovine serum albumin (PDB ID: 3V03) interaction with 5FU. Hydrogen bond interaction with the residues represented in green colored lines and nearby hydrophobic residues in red colored lines. In ligplot, ligand is represented in sticks.

\section{Conclusion}

In summary, the interaction of 5FU with BSA under UVC $(253.7 \mathrm{~nm})$ irradiation and physiological conditions was investigated by using UV-Vis spectroscopy, steady state/time resolved fluorescence spectroscopy methods in this study. The stability of protein was observed to be strong when BSA gets bonded to 5FU under UVC irradiation and further it has been compared with free bovine serum albumin. We have shown that when $5 \mathrm{FU}$ was added in low concentrations $(1 \mu \mathrm{M})$ to albumin solution $(1 \mu \mathrm{M})$, it is capable of reducing protein aggregation induced by UVC to a considerable extent. The protection afforded by $5 \mathrm{FU}$ was effective even at UVC doses much higher than those required for complete inactivation of viruses and bacterial spores. From the molecular modelling studies, the hydrogen bonds between BSA and antimetabolite 5FU are known to be strong up to $70.4 \mathrm{~J} / \mathrm{m}^{2}$ UVC irradiation. Nevertheless, the results presented here clearly indicate that the addition of an antimetabolite (5FU) to the protein (BSA) solution may bring an effective means of protecting albumin from the damaging effects of UVC radiation.

\section{Conflict of Interests}

The authors declare that there is no conflict of interests regarding the publication of this paper. 


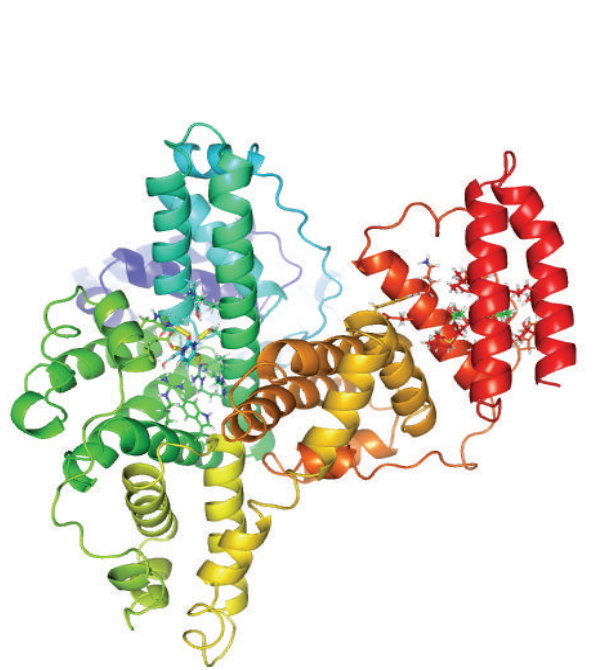

(a)

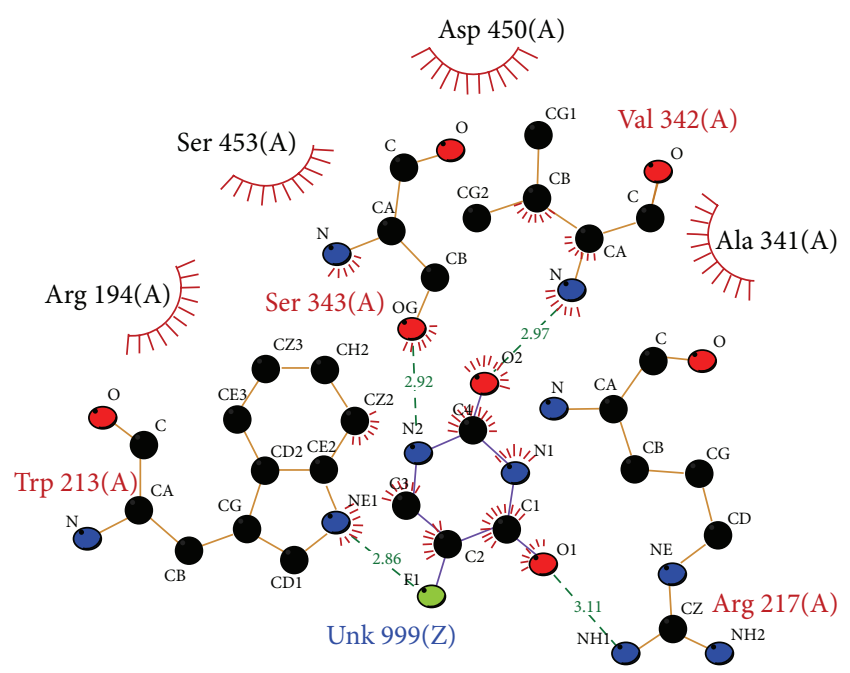

(b)

FIGURE 8: Bovine serum albumin (PDB ID: 4F5S) interaction with 5FU. Hydrogen bond interaction with the residues represented in green colored lines and nearby hydrophobic residues in red colored lines. In ligplot, ligand is represented in sticks.

\section{Acknowledgment}

This study was supported by the Board of Research in Nuclear Sciences, Department of Atomic Energy, Government of India, Project no. 2009/34/38/BRNS/3206.

\section{References}

[1] J. Longstreth, F. R. de Gruijl, M. L. Kripke et al., "Health risks," Journal of Photochemistry and Photobiology B: Biology, vol. 46, no. 1-3, pp. 20-39, 1998.

[2] G. J. Clydesdale, G. W. Dandie, and H. K. Muller, "Ultraviolet light induced injury: immunological and inflammatory effects," Immunology and Cell Biology, vol. 79, no. 6, pp. 547-568, 2001.

[3] K. Yamamoto, T. Furuya, Y. Kameoka, and M. Kawanaka, "Changes in serum levels of sialoglycoproteins in mice exposed to UV-B radiation," Biological and Pharmaceutical Bulletin, vol. 21, no. 9, pp. 1000-1002, 1998.

[4] R. B. Misra, R. S. Ray, and R. K. Hans, "Effect of UVB radiation on human erythrocytes in vitro," Toxicology in Vitro, vol. 19, no. 3, pp. 433-438, 2005.

[5] V. G. Artyukhov, A. A. Pantyavin, and G. A. Vashanov, "Vacuum-UV-radiation-induced structural-functional changes in serum albumin molecules," Journal of Applied Spectroscopy, vol. 68, no. 2, pp. 291-298, 2001.

[6] S.-Y. Lin, C.-J. Ho, and M.-J. Li, "UV-B-induced secondary conformational changes in lens $\alpha$-crystallin," Journal of Photochemistry and Photobiology B: Biology, vol. 49, no. 1, pp. 29-34, 1999.

[7] A. C. Santos Nogueira and I. Joekes, "Hair color changes and protein damage caused by ultraviolet radiation," Journal of Photochemistry and Photobiology B: Biology, vol. 74, no. 2-3, pp. 109-117, 2004.

[8] Y. Watanabe, I. Horii, Y. Nakayama, and T. Osawa, "Effects of cysteine on bovine serum albumin (BSA) denaturation induced by solar ultraviolet (UVA, UVB) irradiation," Chemical and Pharmaceutical Bulletin, vol. 39, no. 7, pp. 1796-1801, 1991.
[9] K. J. A. Davies and M. E. Delsignore, "Protein damage and degradation by oxygen radicals. III. Modification of secondary and tertiary structure," The Journal of Biological Chemistry, vol. 262, no. 20, pp. 9908-9913, 1987.

[10] J. Wang, A. Mauser, S.-F. Chao et al., "Virus inactivation and protein recovery in a novel ultraviolet-C reactor," Vox Sanguinis, vol. 86, no. 4, pp. 230-238, 2004.

[11] P. Caillet-Fauquet, M. D. Giambattista, M.-L. Draps et al., "Continuous-flow UVC irradiation: a new, effective, protein activity-preserving system for inactivating bacteria and viruses, including erythrovirus B19," Journal of Virological Methods, vol. 118, no. 2, pp. 131-139, 2004.

[12] Q. Li, S. MacDonald, C. Bienek, P. R. Foster, and A. J. MacLeod, "Design of a UV-C irradiation process for the inactivation of viruses in protein solutions," Biologicals, vol. 33, no. 2, pp. 101110, 2005.

[13] M. K. Azar Daryany, S. M. Hosseini, M. Raie, J. Fakharie, and A. Zareh, "Study on continuous $(254 \mathrm{~nm})$ and pulsed UV (266 and $355 \mathrm{~nm}$ ) lights on BVD virus inactivation and its effects on biological properties of fetal bovine serum," Journal of Photochemistry and Photobiology B: Biology, vol. 94, no. 2, pp. 120-124, 2009.

[14] M. Yanagi, J. Bukh, S. U. Emerson, and R. H. Purcell, "Contamination of commercially available fetal bovine sera with bovine viral diarrhea virus genomes: implications for the study of hepatitis C virus in cell cultures," Journal of Infectious Diseases, vol. 174, no. 6, pp. 1324-1327, 1996.

[15] H. Hart, K. Reid, and W. Hart, "Inactivation of viruses during ultraviolet light treatment of human intravenous immunoglobulin and albumin," Vox Sanguinis, vol. 64, no. 2, pp. 82-88, 1993.

[16] D. N. Nikogosyan, S. P. Kapituletz, and Y. A. Smirnov, "Effects of ultraviolet laser radiation on Venezuelan equine encephalomyelitis virus," Photochemistry and Photobiology, vol. 54, no. 5, pp. 847-849, 1991.

[17] K. N. Prodouz, J. C. Fratantoni, E. J. Boone, and R. F. Bonner, "Use of laser-UV for inactivation of virus in blood products," Blood, vol. 70, no. 2, pp. 589-592, 1987. 
[18] H. Bian, M. Li, Q. Yu, Z. Chen, J. Tian, and H. Liang, "Study of the interaction of artemisinin with bovine serum albumin," International Journal of Biological Macromolecules, vol. 39, no. 4-5, pp. 291-297, 2006.

[19] H.-D. Bian, H.-R. Zhang, Q. Yu, H. Liang, and S.-H. Ni, "Interaction of $\mathrm{Co}(\mathrm{II})$ with bovine serum albumin under UVC irradiation," Chinese Journal of Chemistry, vol. 25, no. 8, pp. 1116-1120, 2007.

[20] A. Michnik, K. Michalik, and Z. Drzazga, "Effect of UVC radiation on conformational restructuring of human serum albumin," Journal of Photochemistry and Photobiology B: Biology, vol. 90, no. 3, pp. 170-178, 2008.

[21] A. Zuorro and R. Lavecchia, "Protective effect of nicotinic acid on human albumin during UV-C irradiation," Korean Journal of Chemical Engineering, vol. 28, no. 10, pp. 1965-1968, 2011.

[22] L. Liu, L. Xiao, and C. Cao, "Novel magnetic-fluorescent CS$\mathrm{Fe}_{3} \mathrm{O}_{4} @ \mathrm{ZnS}: \mathrm{Mn} / \mathrm{ZnS}$ (core/shell) nanoparticles: preparation, characterization and damage to bovine serum albumin under UV irradiation," Materials Chemistry and Physics, vol. 40, pp. 575-582, 2013.

[23] S. Chinnathambi, D. Velmurugan, N. Hanagata, P. R. Aruna, and S. Ganesan, "Investigations on the interactions of 5fluorouracil with bovine serum albumin: optical spectroscopic and molecular modeling studies," Journal of Luminescence, vol. 151, pp. 1-10, 2014.

[24] Y. Chen, J. D. Mills, and A. Periasamy, "Protein localization in living cells and tissues using FRET and FLIM," Differentiation, vol. 71, no. 9-10, pp. 528-541, 2003.

[25] Th. Förster, "Zwischenmolekulare Energiewanderung und Fluoreszenz," Annalen der Physik, vol. 437, no. 1-2, pp. 55-75, 1948.

[26] L. Stryer and R. P. Haugland, "Energy transfer: a spectroscopic ruler," Proceedings of the National Academy of Sciences of the United States of America, vol. 58, no. 2, pp. 719-726, 1967.

[27] D. Qaiser, M. S. Khan, R. D. Singh, Z. H. Khan, and S. Chawla, "Förster's resonance energy transfer between Fullerene $\mathrm{C}_{60}$ and Coumarin C440," Spectrochimica Acta-Part A: Molecular and Biomolecular Spectroscopy, vol. 77, no. 5, pp. 1065-1068, 2010.

[28] B. Valeur and J. C. Brochon, New Trends in Fluorescence Spectroscopy, Springer, Berlin, Germany, 2001. 

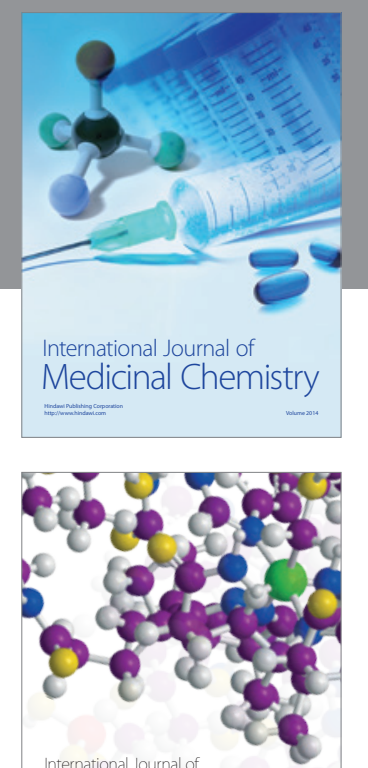

\section{Carbohydrate} Chemistry

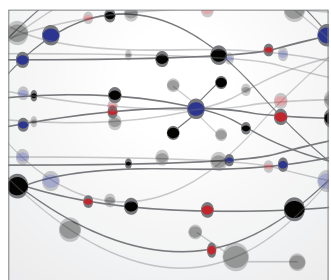

The Scientific World Journal
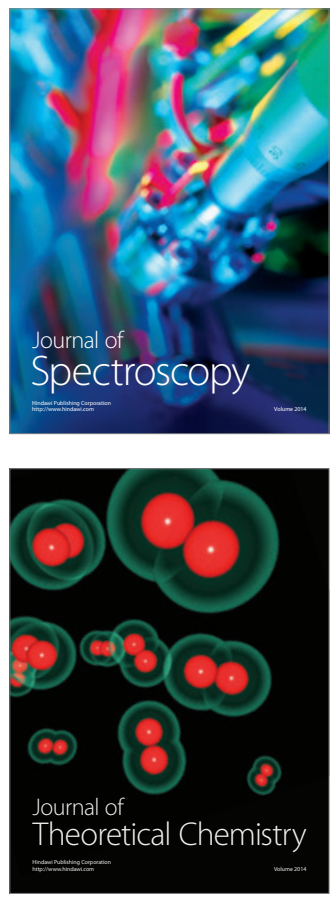
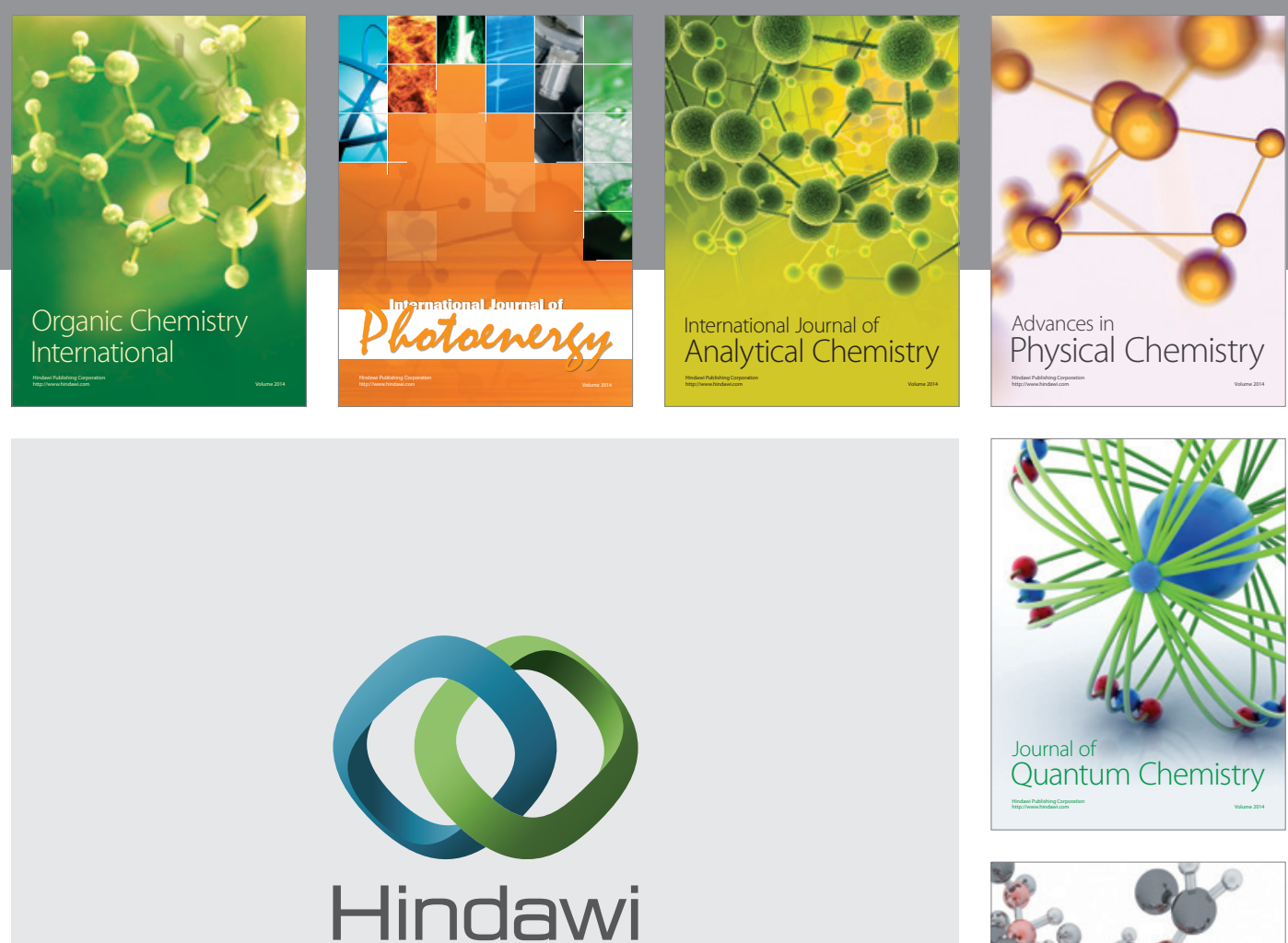

Submit your manuscripts at

http://www.hindawi.com

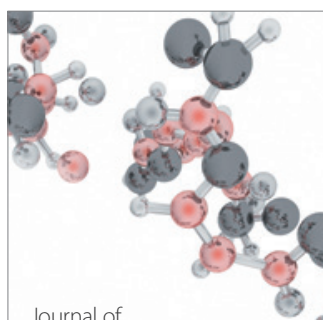

Analytical Methods

in Chemistry

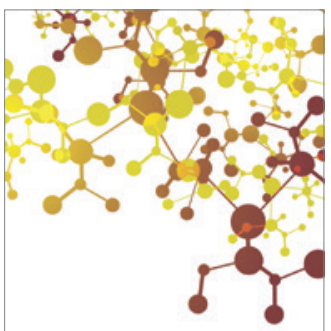

Journal of

Applied Chemistry

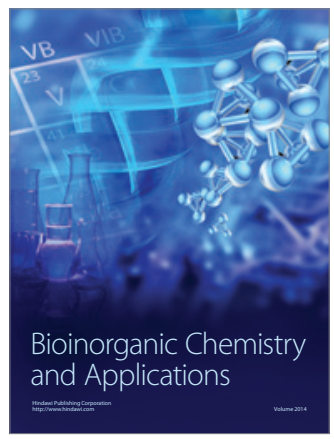

Inorganic Chemistry
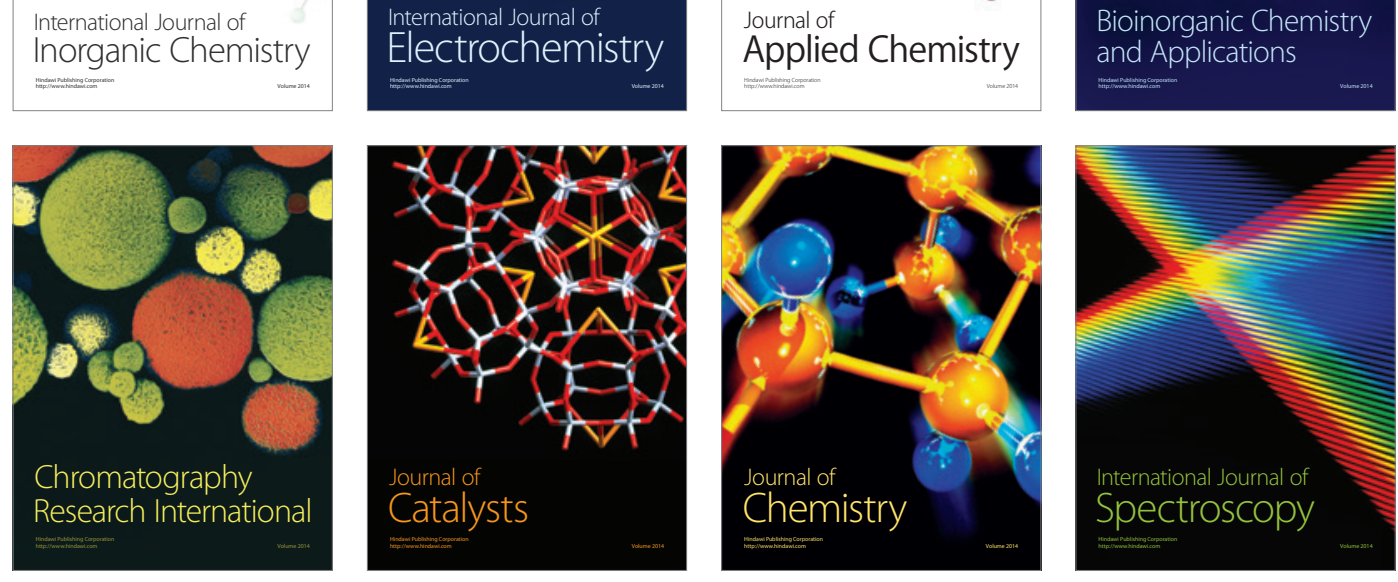